\title{
Interconnection of Media Ecology and Personal Ecology Based on N.Postman's Communication Theory
}

\author{
Elena Agibalova \\ Foreign Languages Academic Department №3 \\ Plekhanov Russian University of Economics \\ Moscow, Russia \\ E-mail: elenagib@rambler.ru \\ Dmitriy Ivlev \\ Federal State Unitary Enterprise \\ State research institute of aviation systems \\ Moscow, Russia \\ E-mail: mcint@yandex.ru
}

\author{
Marina Ivleva \\ Department of History and Philosophy, \\ Plekhanov Russian University of Economics \\ Moscow, Russia \\ E-mail: stm602@yandex.ru \\ Irina Kornilova \\ Department of History and Philosophy \\ Plekhanov Russian University of Economics \\ Moscow, Russia \\ E-mail: irakornilova1972@yandex.ru
}

\begin{abstract}
The article studies the development of media ecology theory being a section of modern information society communication ecology within socio-philosophic concepts of XX-century researchers as well as the development of this theory and its relation to the problem of personal ecology in the works of the American thinker N.Postman. Based on the analysis of problem range and content of the information concept as the most important element of communication as well as transformation of information axiological aspect in the context of modern society as viewed by Postman, a conclusion has been made that the scholar's development of personal ecology was based on the concept of media ecology.
\end{abstract}

Keywords-ecology; information; information society; media ecology; personal ecology

\section{INTRODUCTION}

Modern information society is a complex system of communication flows, supported and disseminated with the help of the latest technology. This system develops social environment of a person, acts as a factor of the formation, regulation and development of consciousness with society in general and human personality, in particular, has a direct impact on social relations and relations between individuals. That is why the theory of social communications today has become the subject of active scientific research and practical implementation.

An important role of socio-cultural communications in the life of modern society explains keen interest in their study by philosophers, cultural studies scholars, and sociologists who identify the ecology of communication among other studied aspects.

\section{DEVELOPMENT OF MEDIA ECOLOGY THEORETICAL POSTULATES IN THE STUDIES OF XX CENTURY SCHOLARS}

First of all, environmental problems were raised in media ecology as studies of the impact exerted by the media, technology and communication on the life of society in the writings of M. McLuhan in 1964 [1]. McLuhan says that media ecology considers how mass media influence the perception, understanding, feelings and values of an individual, and also states that in the communication system, the environment as a subject of environmental research is a complex message system that determines certain ways thinking, feeling and behavior of a person.

Later research in the field of communications ecology, apart from the media, included a broad range of environmental issues in the communicative environment as a whole. For example, at present, studies in the ecology of the language used in the communication process are very widespread. Language and communication are both genetic and constitutive elements of human life, and eco-linguistics has become part of a scientific movement that considers the Earth in general as an ecological entity consisting of different biotopes around the world that are in a state of vital balance.

Research in media ecology has also been conducted intensively by modern scholars. Thesis by C.Nystrom, defended in the US in 1973, can be mentioned as one of the major works in this area. In this work the author defines media ecology as a field of formal scientifically grounded research and formulates a thesis about associations between media ecology, cybernetics and system theory [2]. The ideas expressed by N.Luhmann who analyzed how functional social systems, such as economics, jurisprudence, science, 
education, respond in the course of their evolution to the dialectical contradictions naturally inherent in them, have become widespread [3]. A major role in studying the problems of media ecology belongs to D.Altheid, who identified three aspects of communication ecology in general, namely information transfer technology, the format of communication as the medium that directly transmits information, and social activity; he also paid special attention to the fact that communication depends on the socio-cultural context [4]. Problems of media ecology, the question of its place in the human ecology system in general still remain one of the most important research subjects in modern philosophy $[5,6]$.

\section{Change IN AXIOLOGICAL ASPECT OF INFORMATION IN MODERN SOCIETY}

One of the thinkers whose works contributed greatly to the development of media ecology was the American scientist, philosopher Neil Postman (1931-2003). For more than three decades Postman researched the ontology and epistemology of media ecology, his works were sold out in large editions and are still being republished after the death of the thinker.

Following McLuhan, who defined the famous postulate "medium is a message," Postman makes a philosophical analysis of information in inextricable connection with the means of its transmission, namely, "media." The concept of "media", according to the thinker, includes not only the mass media (they, in Postman's opinion, did not exist until the emergence of capitalist society, while the information itself was produced, generated and transmitted in society since the beginning of its existence) but it also includes any way of communication. Studying the modern stage of social development, namely, the information society, Postman focuses, first of all, on the study of the media. He analyzes how the media changed not only the culture of society in general, but also the individual consciousness of an individual.

Postman pays particular attention to the fact that the mass media in the culture have a dominant influence on the development of its intellectual and social preferences. Moreover, in his opinion, they impose special ideas about reality, first of all, through symbols used to exchange meaningful information. These media metaphors, as defined by the thinker, classify the world for us, put it in order, structure, expand, narrow down, color, and, ultimately, explain what the world is.

Means of communication change both social world and the inner world of people, the system of their ideas about values. The decisive role in the launch of this process, according to Postman, was played by the telegraph in the XIX century, the forerunner of the future information society technology, an invention that allowed a much faster, in comparison with the past, information exchange. However, this new opportunity for a quick exchange of news has also changed the value perception of information: since then, not only something that can be used for successful social and economic life is important and valuable, as Postman said, the way it was until then, but also something that is simply new.

The telegraph generated the idea of context-free information, the idea that the value of information should not be determined by any functions that it can perform when making decisions in the social and political spheres and when choosing the mode of action in them, but it can be caused by public curiosity. As a consequence, the telegraph turned information into a commodity, a "thing" that could be bought and sold, regardless of the possibilities of its further use or its meaning. In the future, the development of broadcasting and television allowed not only learning information quickly, but also spread the context-free perception of this information to mass perception.

Social values regarding the status of information have changed, the values of the possible speed of information dissemination, the scope of the audience covered by it, and the novelty of the data, which are not required to be meaningful and useful, have come to the fore.

According to Postman, in the modern information society certain means of information transfer have reached the status of "metamedium" - a tool that not only directs and determines our knowledge of the world, but also information on how and by what means one can get this knowledge.

\section{IMPACT OF CHANGES IN ONTOLOGICAL}

\section{FUNDAMENTALS OF INFORMATION ON PERSONAL ECOLOGY}

While studying the notion of "ecology", Postman came to the conclusion that it necessarily includes the study of the environment, its structure, content and influence on people. In media ecology, the environment acts as a complex message system that affects the way of thinking, perception and behavior of an individual. This environment prescribes social roles to the individual and identifies the conditions for their fulfillment, often in an implicit, but amid business communication, in an explicit and even formal manner.

According to Postman, the environment developed by the mass media, such as printed media, radio, cinema, television exerts an implicit influence on a personality. It also mostly happens due to the widespread social opinion that in this case there is no communication as such, but only interaction of an instrumental nature, interaction of an individual with the information transmission system. Consequently, the task of media ecology is to identify and explore this concealed influence of the environment organized by the media on personality [7].

Thus, Postman continues a research line identified and established by M. McLuhan, placing the study of media ecology at the level of personal ecology, first stating the very fact of direct media impact on the development and existence of personality, and then proceeding to the question of how the information transmission system influences the deep essence of human personality, what threats are posed by the mass information system to the vital principles of personality considering its data transmission speed and audience coverage. Amusing Ourselves to Death published in 1985 places a special emphasis on this question. In fact, the 
content of the title of this book sounds like "Amusing ourselves to self-destruction" and Postman warns his reader directly about it in the introduction, reminding them about the fears of the famous anti-utopian of the first half of the twentieth century, Aldous Huxley and George Orwell, who portrayed the future society as the place where human personality is destroyed [8].

The reason for such a serious threat, according to Postman, is a change in the existential basis of information that resulted from the wide dissemination of the media, when the general public gained access to its large volumes over a short period of time. The problem, as the thinker believes, is in the purpose that is defined in the process of information dissemination through the media: in modern society, this is the goal of rapid access to any information, regardless of its content, and not the goal of obtaining qualitative, substantial information required for the development of society, its economic relations or to realize the essential needs of an individual. Novelty and the ability to entertain the one who perceives the information have become valuable characteristics of the mass media. As a result, the content of the notion of "being informed" has changed in modern society. According to Postman, the media actually misinforms the consumer - this is not a lie, but the information that is misleading, irrelevant, fragmented, superficial; information that creates a person's illusion of knowing the subject-matter in question, but in fact, leads away from true knowledge.

Therefore, in Postman's opinion, the problem of psychological, political and social impact on personality exerted by the media, especially television and computers, as an environment with the greatest audience coverage, is especially important. This issue is directly related to the ecology of personality, its integrity, focus on values and goals that are essential for the existence of a human and humanity.

Postman continued his research in Technopoly published in 1992. Over the past decade, since the publication of the previous book, computerization has become an integral part of socio-economic life, however, it aggravated, according to the scholar, those problems of personal ecology that were determined by the rapid development of the media during the twentieth century. The term "technopoly" is defined by Postman as the current stage of the information society development, while its representative, the so-called "technopolist", is a person who is convinced that getting as much information as possible is the only relevant global need.

While not denying the importance of information and the development of technology for society, Postman draws attention to threats posed to the existence of human personality that exist in the modern information world. These threats result from the fact that an individual has ceased to be the most important value, and this place was taken by information.

Innovative technology and means of information transfer are created primarily to generate, store and distribute data of large volumes with an unprecedented speed. When asked what problem the information solves, the answer is: "How to receive and distribute as much information as possible, faster and more conveniently for the consumer". As a result, information receives a metaphysical status, as a means and purpose of human creativity.

As a consequence, the ocean of information around us has become a source of information garbage: information that is not only incapable of answering the fundamental questions of human existence, but is useless even for solving everyday "mundane" problems [9]. Thus, the media ecology and personal ecology receive a new point of contact: "cleansing" of information from information noise, as meaningless and not having intellectual nor practical benefits data, inseparable from the qualitative existential characteristics of the individual.

In other words, in the environment where Technopoly flourishes, the connection between information and human goal-setting is ruptured, i.e. information appears randomly, not specifically targeted, in huge volumes, at high speed of transmission and distribution, and at the same time it is cut off from any theory, meaning and purpose. In modern culture, the idea of human progress has been replaced by the idea of technological progress, and the goal of information consumption is not getting rid of ignorance and prejudice, but adaptation to the requirements of new technologies. We consume information, being unable to control this process, without thinking that society can suffer not only from the lack of information but also from its excess. In the pursuit of information for the sake of information as such, social, psychological and moral issues fade into the background.

\section{DEVELOPMENT OF PERSONALITY AND MEDIA CONSCIOUSNESS}

Postman sees the only possible solution to this antihumanist situation in the life of modern society in the development of the media consciousness of society in general, and individuals, in particular. Media consciousness means the ability to think critically, control information, identify data in its huge flow that is really important and substantial in terms of consequences for the life of an individual and society, not to be a passive consumer of information of any content with its main advantage of being new. This task requires the education of an individual already at school, both secondary and higher, with a necessary change in the curriculum for these purposes.

Today, media consciousness of instructors, as Postman says, is focused on how television and computers can be used in teaching and learning monitoring (it's interesting that over the past thirty years since the book was written, despite rapid, often uneven changes in the information environment, practically nothing has changed in this matter, except that the attention of modern instructors is focused not on television, but on the possibilities of computerizing training and using the Internet to reduce direct communication with the instructor in the educational process). While the essential question, according to the scholar, should be exactly the opposite: how can we use education, training for the development of personality, abilities of critical thinking in 
order to learn to control information obtained through the media, television, computers? [10].

While a person in the information society does not think about existential issues in the flow of information, in fact, society and the state control this flow through a special structure of procedures and social technology that help achieve the desired result in the management of the information society. These include IQ tests, the Unified State Exam system, unified standards of conduct, widely used classifications, and opinion polls. Their role in reducing the diversity and quality of information that society receives is often unnoticed, and thus the consequences of this situation are also unnoticed: their role in reconsidering traditional concepts about the individual.

As Postman fairly notes, no test can serve as a measure of the human intellect, since intellect as a general concept is used to determine the ability of an individual to solve real life problems in various non-standard new situational contexts. Depending on the conditions of the situation and the type of problem that requires solution, the same person can, according to their abilities, act successfully or fail. If we are forced to believe that with the help of the test it is possible to identify the exact "amount" of intellect, the intellect becomes no more than just points obtained as a result of testing. The test turns an abstract and multifaceted concept into an exact technical term, and deprives itself of its essence.

\section{CONCLUSION}

The problem of the impact that technology has on the development of society and personality is one of the most common ones in modern philosophical studies, and has received a wide variety of solutions and evaluations in the works of numerous thinkers. A qualitative feature of $\mathrm{N}$. Postman's views is that he specifies the concept of innovative technology primarily as technology of information transfer and while examining the specific features of its existence within the limits of media ecology studies, traces, among other things, the problems of human existence determined by its impact.

According to Postman, the modern information society has developed conditions under which the value of developed and educated human personality disappears, being replaced by a non-critical consumer of information, whose spiritual life is successfully controlled by society. Therefore, the scholar relentlessly draws the attention of his readers and followers to the vital importance of developing media ecology, the ecology of communication in general. Given the active impact of media on an individual and society [11,12], social values and culture [13], this position of Postman's philosophical views remains relevant up to this day.

\section{REFERENCES}

[1] McLuhan, M. Understanding media. New York: Mentor. 1964.

[2] Nystrom, C. L. Toward a science of media ecology the formulation of integrated conceptual paradigms for the study of human communication systems. Doctoral Dissertation, New York University 1973.

[3] Luhmann N. Ecological communication. Chicago, University of Chicago Press. 1989.

[4] Altheide D.L. (1994) An Ecology of Communication: Toward a Mapping of the Effective Environment. The Sociological Quarterly, Vol. 35, No. 4 (Nov., 1994), pp. 665-683

[5] Barkova E., Ivleva M., Buzskaya O., Buzskij M. Ecology of culture in the space of social and humanitarian knowledge. Proceedings of the 2017 2rd International Conference on Contemporary Education, Social Sciences and Humanities 2017. C. 12-15.

[6] Ponizovkina I. Social myth in modern society. Proceedings of the 2016 3rd International Conference on Education, Language, Art and Inter-cultural Communication (ICELAIC 2016) Advances in Social Science, Education and Humanities Research. Xiamen. 2017. C. 648653.

[7] Postman, N. The reformed English curriculum. In A. C. Eurich (Ed.), High school 1980: The shape of the future in American secondary education (pp. 160-168). New York, NY: Pitman. 1970.

[8] Postman N. Amusing ourselves to death: Public Discourse in the Age of Show Business, Penguin books. 1985.

[9] Postman N. Technopoly: The Surrender of Culture to Technology. New York: Knopf. 1992. P.69-70

[10] Postman N. The Humanism of Media Ecology. Keynote Address Delivered at the Inaugural Media Ecology Association Convention Fordham University, New York, New York June 16-17, 2000. Proceedings of the Media Ecology Association, Volume 1, 2000

[11] Ivlev V., Oseledchik M. Methodological principles for the introduction of modality categories in modern scientific cognition. 3rd international conference on arts, design and contemporary education (ICADCE 2017). General chairs: Alexandr Yakoupov, Xiaojie Wei, Olga Chistyakova, Galima Lukina, Oleg Filippov. 2017. C. 541-545.

[12] Koshkin A.P., Yablochkina I.V., Kornilova I.M. Integration of students' and professors' interests in the context of university corporate regulations International Business Management. 2016. T. 10. № 22. C. 5432-5441.

[13] Novikova E.Y., Malakhova E.V., Galukhin A.V., Kostin P.A. Physical culture values in professional education system of university of economics. Theory and Practice of Physical Culture. 2017. № 5. C. 11 . 